\title{
Spatio-temporal determinants of mental health and well-being: advances in geographically-explicit ecological momentary assessment (GEMA)
}

\author{
Thomas R. Kirchner ${ }^{1,2,3}$ (1) Saul Shiffman ${ }^{4,5,6,7}$
}

Received: 28 June 2016/Accepted: 5 August 2016/Published online: 24 August 2016

(c) The Author(s) 2016. This article is published with open access at Springerlink.com

\begin{abstract}
Purpose Overview of geographically explicit momentary assessment research, applied to the study of mental health and well-being, which allows for cross-validation, extension, and enrichment of research on place and health.

Methods Building on the historical foundations of both ecological momentary assessment and geographic momentary assessment research, this review explores their emerging synergy into a more generalized and powerful research framework.

Results Geographically explicit momentary assessment methods are rapidly advancing across a number of complimentary literatures that intersect but have not yet converged. Key contributions from these areas reveal tremendous potential for transdisciplinary and translational science.
\end{abstract}

Thomas R. Kirchner

tomkirchner@nyu.edu

1 College of Global Public Health, New York University, 41 E. 11th St., 7th Floor, New York, NY 10003, USA

2 Center for Urban Science and Progress, New York University, New York, NY, USA

3 Department of Population Health, New York University Medical Center, New York, NY, USA

4 Department of Psychology, University of Pittsburgh, Pittsburgh, PA, USA

5 Department of Psychiatry, University of Pittsburgh Medical Center, Pittsburgh, PA, USA

6 Department of Pharmaceutical Sciences, University of Pittsburgh School of Pharmacy, Pittsburgh, PA, USA

7 Clinical and Translational Science Institute, University of Pittsburgh, Pittsburgh, PA, USA
Conclusions Mobile communication devices are revolutionizing research on mental health and well-being by physically linking momentary experience sampling to objective measures of socio-ecological context in time and place. Methodological standards are not well-established and will be required for transdisciplinary collaboration and scientific inference moving forward.

Keywords Ecological momentary assessment (EMA) . Geographic momentary assessment (GMA) .

Geographically explicit ecological momentary assessment (GEMA) · Geographic information systems/science (GIS) · Spatio-temporal determinants of health $\cdot$ mHealth

\section{Introduction}

The stuff of the mind is the stuff of the world, and so the investigation of the rich structure of the world provides a clearly observable and empirically tractable-if not royal—road into the hidden countries of the mind.

Tooby \& Cosmides, 1992

The Psychological Foundations of Culture

Lifespan disparities in excess of 10 years between residents of neighborhoods characterized the lowest versus the highest levels of socio-economic status (SES) have persisted in the United States for decades [1, 2]. Findings from three large longitudinal studies [2-5], together spanning the period from 1979 to 2014, indicate that lifespan disparities are largely due to neighborhood residents' moment-to-moment mental health and wellbeing, insofar as these factors drive behavioral decisions-whether to exercise or smoke cigarettes, what to 
eat and drink, and whether to continue pursuing an education. These studies also converge to suggest that neighborhood characteristics promote and protect against these behavioral health determinants-especially within low-SES areas. Adjusting for a range of demographic factors, Chetty et al. [1] found that lowincome residents of otherwise affluent and highly educated cities such as New York and San Francisco were protected from the loss of as many as 5-years of life relative to low-income residents of less-affluent cities such as Detroit, Michigan or Gary, Indiana. The mechanisms behind this finding are undoubtedly complex, exposing how little we know about the way neighborhoods shape subjective experience and ultimately determine the psychological and physical health of their residents.

This paper presents an overview of the way ecological momentary assessment (EMA [6-9]) methodologies have been used to study the interplay between individuals' experience and their evolving environmental surroundings, with specific emphasis on the measurement of mental health and well-being. With traditional roots in real-time experience sampling [10-12], EMA primarily involves administration of self-reported survey items in real-life settings (i.e., collected as part of subjects' ongoing activities of daily living). More recently, technological advances have led to the development of geographic momentary assessment (GMA) methods, which are founded on the notion that individuals can be characterized by a spatiotemporal probability distribution-time spent amongst a set of places, each with their own geographic boundaries and temporal characteristics (e.g., duration and cyclic regularity of visits) [13-16]. Combined within a common, geographically explicit ecological momentary assessment (GEMA) framework, ${ }^{1}$ EMA and GMA dovetail with a number of socio-ecologic theoretical models [18-23]-together providing an explicitly geographic measurement framework that can be leveraged to study the way people and places reciprocally determine each other over time [24]. This GEMA framework is more than the raw Cartesian coordinates that distinguish it from traditional EMA, and is often most useful for the study of "places" imbued with meaning by subjects-representing each subject's personal eco-system, itself populated by an array of spatially weighted geographic correlates with known sociocontextual significance.

\footnotetext{
1 This framework separates EMA-only and GMA-only research from GEMA studies that implement both. The combination of EMA and GPS tracking was referred to as GMA in one previous paper [17], which is included within the GEMA section of this review.
}

\section{Neighborhoods to neurons: ecological momentary assessment of mental health}

The rise of EMA methodology in the behavioral health sciences is largely due to the fact that it documents subjective experiences, including symptoms of mental distress, in natural environments. The primal brain structures designed to protect us from threats via affective signals like fear, disgust, and anger evolved within ancestral environments $[21,25,26]$. The adapted human mind is preprogrammed to identify fearful stimuli, and given that emotional reactivity becomes conditioned under chronic exposure to environmental conditions, cultural anthropologists and environmental psychologists have written extensively on the idea that study of structural and cultural environments can improve our understanding of mental health [27-30]. This includes the evolution of addictive and maladaptive eating behaviors, which are exacerbated by modern "toxic" environmental conditions, often intentionally designed to cue deeply ingrained desires for consumption [31, 32].

Standard diagnostic practice within psychiatry and clinical psychology is based on structured psychometric interviews that assess the frequency and severity of affective and behavioral symptoms over a specified period of time-generally the past 2-weeks for acute symptoms. This approach requires respondents-sometimes in acute distress-to describe complex patterns of symptom expression. A limitation of this is that retrospective recall often diverges from reality, as evidenced by EMA research on symptom fluctuation [33, 34], and mobile interventions [35-38]. Clinical researchers have utilized EMA to study a range of psychopathological symptom profiles. Most work has focused on symptoms related to additive disorders [8] or depression [39, 40], but studies have also assessed symptoms in patients suffering from anxiety [41], schizophrenia and psychosis [42-44], chronic pain [45], attention deficits [46], eating disorders [47], and personality disorders [48].

An ongoing challenge is that while symptom variation across socio-ecological circumstances is at least as important as their basic frequency and duration, self-reported EMA surveys are not well-suited for systematic documentation of symptom fluctuation over both time and place. EMA protocols often include survey items that assess certain socio-ecologic circumstances, but the full range of structural and cultural factors that could be involved extend well beyond what an individual could be expected to perceive, much less report with fidelity (e.g., ambient light and air quality; neighborhood disorder; local social norms) [49]. Even if complete information were available to respondents, the affective neuroscience 
literature now strongly supports Zajonc's (1980 [50]) dictum that "preferences need no inferences", suggesting that humans generally lack conscious, introspective awareness of the cognitive underpinnings of their feelings [51-53].

Geographically explicit EMA (GEMA) integrates EMA with GMA methods and thus geographic information system (GIS) science, allowing for cross-validation and enrichment of research on place, well-being, and health. This is accomplished with mobile geographic location technologies that physically link participants to their current position in two-dimensional space. This geographic link operationalizes the "ecological" aspect of EMA, such that geographic locations can be quantified precisely and then attached to corresponding sources of socio-ecologic data. Setting the stage for this methodological integration, health-related GMA research has advanced rapidly over the past 10-years, including considerable work that focuses on momentary measurements of individuals' geographic location.

\section{Geographic momentary assessment (GMA)}

\section{Mere mobility}

The physical touch-point between individuals and their surroundings and thus the foundational nexus of all personplace dynamics is their geographic location-shifting over time between periods of stability and periods of movement. The basic science of human mobility extends back through decades of work on international migration and macroeconomic trends $[54,55]$, and has recently been reignited by new geographic location technologies and resultant sources of data. Even with as little as the timing and location of cell-tower transmissions, for example, computational social scientists have shown that passive observation of call-data records from cellular telephone providers can be used to predict individual movement patterns and even identify social networks [56-59]. This important work is establishing precise metrics for the study human mobility, although it suffers in some ways from an aggregated, macro perspective some have used to question its societal impact $[60,61]$.

The use of geographically explicit human mobility data for the study of health was pioneered around the turn of the century by environmental exposure scientists interested in individual-level patterns of exposure to air and water pollution [62-69]. While exposure science work of this kind has focused almost exclusively on biological exposures to environmental pathogens-sometimes referred to as the "exposome"- there is growing recognition that linking purely chemical conceptions of the exposome to the broader ecosphere or "eco-exposome" can foster transdisciplinary perspectives and possibly novel insights regarding health and place [70-72]. For example, behavioral scientists interested in effects of the built environment on physical activity levels have also contributed a great deal to research on geographically explicit measures of mobility and place [73-81], and extensions of this work are beginning to link individual mobility data to a range of geographic features correlated with diet and drug-use [82-86].

While their eventual convergence seems inevitable, computationally oriented disciplines founded on big-data analytics are too often disconnected from disciplines considered the standard-bearers of research on place and health. A field that some refer to as spatio-temporal epidemiology has grown from roots in sociology, geography, public health, and statistics, [87, 88] while other wellestablished fields such as psychiatry, clinical psychology, and environmental exposure science continue to emphasize connections between socio-ecological circumstances and mechanisms operating below-the-skin [38, 70]. Division between disciplines notwithstanding, it is encouraging that all share strong conceptual and methodologic interest in the way that individuals' geographic location meanders over time, providing the foundation for a common ecologic framework for the design and implementation of health research.

\section{Geographic correlates}

Long before interest grew in the way street networks affect physical activity patterns, urban planners and sociologists had recognized the symbiotic relationship between pedestrian traffic and municipal development [89, 90]. For instance, Jane Jacobs described the way "short blocks" within cities determine the flow of residents and thus catalyze opportunities for retail businesses to emerge and grow [90]. Street network structures and the associated access that pedestrians have to risk and protective factors in their local area-often referred to as an area's walkability-provides an example of the way geographically distributed determinants of health can be linked to the wellbeing and health of local residents [91, 92]. Even in the absence of data on individual travel routes, indices of walkability can be a useful approximation of potential opportunities for access, and can thus provide a means to quantify differential access to risk and protective factors within and between neighborhoods.

A useful example concerns walking routes to and from school, which has been identified as an important Industry vector for the sale of retail products. In New York City, which consistently ranks among the most walkable US cities, as many as $61 \%$ of six graders walk or bike to school [92, 93]. As adolescent decision-making autonomy 
grows in combination with a developing system of attitudes, beliefs, and emotional self-regulatory control, adolescents' point-of-sale purchase decision-making is heavily influenced by retail access and marketing [94-96]. For example, point-of-sale food options vary across neighborhoods [97, 98], and the location of neighborhood food sources has been associated with adolescents' food intake [80, 99-101] and overweight status [102-107].

Most studies of this kind correlate cross-sectional survey data with neighborhood data from within an arbitrary geometric area around schools [108, 109], or within walkable activity-spaces estimated with spatial network analytics [103, 107, 110, 111]. Similar approaches have been used to examine associations between product consumption and the corresponding geographic density of retail tobacco [112-121] and alcohol outlets [122-124]. A key assumption here is that the spatial concentration of health-risk and protective factors sufficiently approximates and is thus representative of individual-level exposure levels. An alternative is that observed associations between product landscape densities and use patterns are not driven by individual-level point-of-sale interactions per se, but by unobserved, shared determinants of both product availability and use among those who reside in different neighborhoods [125].

Studies contrasting the uncertainty of GIS-based exposure estimates have found that approximated activity space methods do not correspond well with real-time exposure data [69, 80, 81, 126-129]. For example, our group has developed methods for direct comparison of retail product exposure estimates based on residential approximation versus continuous observation of geospatial contact $[130,131]$. Results of one analysis indicate that as much as $55.2 \%$ of the variance in real-time exposures was not explained by residential density levels, suggesting that purely residence-based analyses misclassify large amounts of exposure data. Thus, while latent conceptualizations of neighborhood walkability and risk factor access can enrich our understanding of health and place, caution must be taken when drawing inference about underlying mechanisms in the absence of data on actual person-place dynamics.

\section{Geographically explicit ecological momentary assessment (GEMA)}

Whether and how exposures to retail products and other neighborhood risk and protective factors impact residents' behavior remains poorly understood [101, 108]. Access to products may affect behavioral decision-making in a way that is incidental-operating by cueing spontaneous purchase decisions-or as a matter of convenience, influencing deliberate decisions to selectively seek out one product or another. One way to investigate this would be to examine actual mobility routes in conjunction with EMA purchase reports, in an attempt to identify cases wherein subjects deviate from their established routes when seeking products. Note that this leverages within-subject data to ascertain the geospatial context of product purchases and draw inferences about geographic correlates, an approach not possible with cross-sectional or macro-aggregated data. Alternatively, a mixed-methods approach that has subjects annotate a map of the places they visit could be used, alone or supplemented by EMA reports regarding intentional versus spontaneous purchases [132, 133].

Quantifying the interactive influence of geographically dispersed neighborhood factors on health is not possible with layered density approaches alone. Neighborhood walkability may increase activity and reduce overweight, while it might simultaneously expose kids to air pollution and retail products in a way that varies from neighborhood to neighborhood $[65,134]$. Interactions of this kind happen at the individual level, and it is at that nexus point that multilevel influences can be contrasted more directly. A recent, policy-oriented example comes from Pearson et al., working in Washington, DC, who incorporated geographically explicit information on local smoke-free policies and socially imposed smoking restrictions alongside continuous GMA of participant locations and EMA reports of cigarette and electronic cigarette use [132].

A handful of research groups have implemented fullscale GEMA protocols for the study of addictive drug-use behaviors [82, 83, 132, 135-138]. Among the most consistent findings from this body of work is the central role played by motivational drive states like drug-use craving [82, 135, 136, 138, 139]. This supports the notion that neighborhood product density plays a direct role, triggering craving and thus purchase-decisions, rather than simply enabling purchases that were planned ahead of time. Considered within a broader socio-ecologic framework, a cued-craving model of neighborhood influence is likely an over-simplification, as the presence of craving implies an established and often firmly engrained pattern of use. It has been observed that predictors of behavioral maintenance and cessation are often different than predictors of initiation [140, 141], spawning new questions about the impact of neighborhood factors on drug-use initiation over the course of early childhood and adolescence.

Extending beyond the retail product landscape, GEMA can be used to construct a geo-social tapestry that includes local policies, park conditions, crime, and other systems level economic factors that cannot be captured by EMA alone. In a series of GEMA studies, Preston et al. supplemented standard measures of drug craving and use with information about neighborhood conditions and 
physiological correlates like stress [17, 142]. Findings extend other EMA work on precipitants of drug use, incorporating the ways that stressful neighborhood settings underlie and can moderate their effects [143, 144]. Regarding etiology, available evidence suggests that the formation of maladaptive, cued associations with a specific substance or product depends on self-regulatory processes [145-147], in the sense that individuals facing stressful environmental conditions are more likely to utilize coping resources that are readily available within the same ecologic system that exacerbated their distress in the first place.

Mobile communication devices will continue to revolutionize research on mental health and well-being by linking momentary experiences to objective measures that can be collected unobtrusively [135, 148-150]. Notable examples come from recent research on symptoms of depression and anxiety [149, 151]. Pentland et al. [149, 150] and Mohr et al. [148, 152] have demonstrated that passive sensing of GPS and other cell-phone usage metrics can be used to classify symptom severity. Beyond mere classification, Madan et al. [150] confirmed that Bluetooth-detected social interactions and movement patterns were associated, and that in some cases EMA-reported stress levels actually preceded stress-related behaviors such as travel to locations known to provoke anxiety.

Psychosocial stress is known to increase vulnerability to environmental pathogens [153, 154], but there has been less emphasis on the feedback loop whereby environmental exposures exacerbate stress and cognitive function more broadly. Air pollution exposure has been linked to symptoms of stress and depressed mood [155-159], raising the prospect that ecologic measurement of emotional wellbeing could be leveraged to investigate the cognitive impact of exposure to air pollution. For example, Bullinger et al. [158] implemented a geographically explicit daily diary protocol with small samples of healthy adults from polluted and non-polluted regions of Bavaria, assessing self-reported mood (including stress and "annoyance") along with a range of ambient pollutant concentrations and weather conditions each day over a 2-month period. Though a small preliminary study, results suggested timelagged effects of elevated pollutant exposure on depressed mood and elevated stress.

GEMA methods have also been utilized by physical activity researchers, although the focus of mobile survey reports in these studies have most often been restricted to behavioral assessments associated with physical activity patterns [84-86, 160-163]. Regardless, it is interesting to consider whether the same mechanisms believed to drive the well-known connection between physical activity and subjective well-being (e.g., cardio-pulmonary function)
[164-168], may also explain the potentially detrimental impact of exposure to air pollution on mental health [154]. Studies are needed to explicitly measure the degree that a positive association between exercise and psychological well-being may be diluted by simultaneous exposure to particulate matter in the air. This is an example of a transdisciplinary research question involving multivariate geographic correlates that could be readily addressed with GEMA methods. The ability to systematically contrast geographic correlates that may produce countervailing effects with unknown population-level impact is among the key advances offered by the GEMA framework.

\section{Risk and resilience: neighborhood effects}

Researchers and community stakeholders have long suspected that impoverished neighborhood conditions have a detrimental impact on the mental health of residents [169, 170]. Only recently have longitudinal studies begun to systematically document the way chronic exposure accrues within environments that are devoid of resources and periodically traumatic [110, 171, 172]. This literature operationalizes neighborhood disorder via systematic measurement of street-level conditions, including damage to buildings and other structures, litter, and criminal activity [173]. Viewed through this lens, retail outlets are not simply isolated drug-use cues or access points, but are elements of a broader ecologic system [146, 147, 152]. Alcohol retailers, for instance, cue and enable drinking, while they also potentiate deviant behaviors, interpersonal violence, and crime [169, 170, 174-177].

Longitudinal documentation of neighborhood disorder and mental health has revealed significant person-level variation in resilience to neighborhood stressors that is due to both the type and severity of stressors involved [178-180]. This familiar pattern is consistent with other ecological exposures work, once again highlighting the need for GEMA research designed to connect multi-level sources of information extending down from neighborhood conditions to ongoing subjective experience. It would be useful, for instance, to investigate the real-world circumstances under which residents experience feelings of safety, control, and freedom to improve their circumstances, all of which have been linked to protection against substance misuse and other mental health problems [181-185].

Ecological research on the effects of natural and manmade disasters on neighborhoods provides a contrasting perspective on neighborhood conditions and mental health, results of which suggest that the effects of severe residential damage are similar to effects of poverty and neighborhood disorder [186-188]. One study assessing the impact of Hurricane Sandy used tablets to conduct 1000 
probability-based household surveys, randomly selected to represent the population of residents located within a geographic catchment extending along the entire coastal area affected by the storm. Findings indicate that children residing in homes that were damaged by the storm were particularly susceptible, with rates of depressive symptoms 2-4 times that of children from homes that incurred no damage [159]. It is noteworthy that researchers in this area often focus on psychological resilience and recovery [189, 190], and have developed instruments for assessing individual susceptibility to environmental adversity $[22,191]$, resources that may be useful to implement within GEMA research on the mental health of those in low-resource, disordered communities more broadly.

\section{Discussion}

Advances in GEMA methods correspond with novel transdisciplinary "team" science approaches to mobile health (mHealth) research and practice more generally [192]. EMA, like any self-report method, is subject to the limitations of human respondents' perceptual filters. People cannot report that which they are unaware [49], and what they do report is a subjective account of ecological context. Geographic momentary assessment (GMA) of real-time locations provides an objective relational connection to place, and thereby a rapidly expanding array of data, promising to transform environmental and health research and practice in the years to come.

Within a combined GEMA framework, relational data of this kind can enrich our perspective in absolute terms while also cross-validating EMA responses. EMA situational reports need not be relied on as objective ecologic measures, and instead can be valued precisely because they are free to diverge from other sources of cross-referenced ecologic data. National Oceanic and Atmospheric Association weather archives may indicate that it was "mostly sunny" on the afternoon of a certain day within a certain zipcode, but what is more interesting is the variation among subject reports at that same moment-some of whom, perhaps those who are characterologically pessimistic or just feeling down, may interpret the sky as "partly cloudy".

\section{Methodological considerations}

Careful consideration of the distinction between traditional EMA and GEMA reveals a number of implications that extend well beyond the basic idea that EMA surveys can be linked to geographic coordinates. First of all, because the inherent purpose of GEMA is research on the multivariate association between geographic correlates and subjective experience, researchers must consider sources of both real and spurious spatial autocorrelation, or the clustering of similar values as a function of their geographic proximity. Statistical inference in the presence of spatial autocorrelation requires valid information about the spatio-temporal distribution of the variables involved [193, 194]. Even when geographically explicit, a research protocol that only collects location information within EMA reports is blind by design to subjects' baseline exposure to geographic correlates when EMA reports are not completed (i.e., the vast majority of the time). Without person-level data on the baserate of geographic exposures, inference regarding associated EMA reports can be misleading [195], for the same reasons that the predictive power of a diagnostic survey instrument (e.g., a brief depression screener) is directly related to the baseline prevalence of the disease within the group being tested. For example, given a hypothetical sample of depression ratings that are consistently elevated, drawn from two cities that have very different ambient air pollution levels, failure to account for spatial autocorrelation might lead one to conclude that air pollution is linked to depression in one city but not the other; that is, that air pollution and depression are associated in the polluted city, when in fact we know a priori that the subjects from both cities were equally depressed regardless.

One way EMA researchers have drawn inference about place-based, situational correlates is by contrasting random or otherwise time-based EMA reports (the within-subject control) with reports that are associated with a correlated event of interest (the within-subject case) - such as a druguse event [140,196, 197]. When an additional stream of data that is spatially distributed is incorporated it becomes necessary to evaluate the degree to which corresponding EMA reports are themselves spatially representative. Just as probability-based sampling ensures that opinion survey respondents are representative of the spatially distributed population from which they are drawn, ideally the timing and frequency of GEMA reports are reasonably proportionate to the underlying baserate that an individual spends time in the context of geographic correlates under study. GEMA protocols that include continuous geolocation monitoring provide complete geographic exposure information and thus the ability to account for person-level baserates. When necessary, GEMA methods can even be used to oversample EMA reports accordingly via real-time geographic survey-prompting procedures.

Data security and privacy will remain important considerations for the foreseeable future [198-201]. While the research subject consent process is central, the inherently identifiable nature of individual geographic mobility data presents new ethical challenges, particularly regarding 
participants' access to, understanding of, and control over their own information [202]. Nonetheless, there are data security and processing methods that can substantially minimize risks by "masking" and ultimately removing geographic information altogether. Encryption and geographic masking procedures that remove geolocation precision from raw location data provide security protection during the data collection, processing, and analysis phases the research. Perhaps more importantly, location coordinates can be pre-processed in a way that allows selective extraction of research-relevant indicators while sensitive location information is stored separately and ultimately destroyed. For example, participants' geographic location data can be used to generate exposure counts that are completely devoid of geographic or otherwise identifiable information. Thus, geographic precision can be tailored such that the spatial resolution of location coordinates is the minimum level required to address a research question deemed to have a societal impact that is significant and commensurate to the risks of the research.

\section{Conclusions}

Not unlike the data on geographic variation in lifespan $[1,2]$, international surveillance data indicate that markers of well-being like subjective happiness are much more prevalent in some nations than others, varying significantly between municipal areas [203-205]. Geographically explicit, real-time reports of well-being are also being aggregated from social media such as Twitter, confirming patterns observed via conventional surveys [206-208]. More intriguing, geographically referenced photos shared on the Internet are emerging as a public health surveillance tool [209-211], and together, these new geographicallyexplicit indicators suggest that not only does subjective well-being vary as a function of place, but that the temporal dynamics of this association unfold differently over the course of the day [206, 207, 210].

For cultural anthropologists and geographers, as well as sociologists, urban planners, and others who specialize in the study of the way places have been developed by people, it is natural to focus on dynamic interactions between people and places, including the intersection of place and health. Yet the traditional frame of reference is spatially and temporally macro, documenting the relatively slow evolution of local health related-norms, for example, or the differential impact of large-scale public policies that unfold over years or decades. The existence of macro-level trends notwithstanding, the meso- and in some cases micro-level dynamic processes nested within the cyclic daily routines of individuals can increasingly be captured by modern technologies, and it is interesting to consider the degree to which variance in population health outcomes will be better accounted for by a geographically explicit measurement framework that weighs the reciprocal push and pull of both the macro and the micro $[19,212]$.

Acknowledgments The authors are indebted to Alexandra Guttentag for her assistance preparing this paper. This work was supported by the US National Institutes of Health: National Institute on Drug Abuse, National Cancer Institute, and Office of Behavioral and Social Science Research; R01DA034734 \& R01DA040930 (TRK). SS provides consulting to ERT, which provides electronic diary services for research.

\section{Compliance with ethical standards}

Conflict of interest On behalf of all authors, the corresponding author states that there is no conflict of interest.

Open Access This article is distributed under the terms of the Creative Commons Attribution 4.0 International License (http://crea tivecommons.org/licenses/by/4.0/), which permits unrestricted use, distribution, and reproduction in any medium, provided you give appropriate credit to the original author(s) and the source, provide a link to the Creative Commons license, and indicate if changes were made.

\section{References}

1. Chetty R, Stepner M, Abraham S et al (2016) The association between income and life expectancy in the United States, 2001-2014. JAMA 315:1750-1766. doi:10.1001/jama.2016. 4226

2. Rogot E, Sorlie PD, Johnson NJ (1992) Life expectancy by employment status, income, and education in the National Longitudinal Mortality Study. Public Health Rep 107:457-461

3. Sorlie PD, Backlund E, Keller JB (1995) US mortality by economic, demographic, and social characteristics: the National Longitudinal Mortality Study. Am J Public Health 85:949-956. doi:10.2105/AJPH.85.7.949

4. Jackson SA, Anderson RT, Johnson NJ, Sorlie PD (2000) The relation of residential segregation to all-cause mortality: a study in black and white. Am J Public Health 90:615-617. doi:10. 2105/AJPH.90.4.615

5. Murray CJL, Kulkarni SC, Michaud C et al (2006) Eight Americas: investigating mortality disparities across races, counties, and race-counties in the United States. PLoS Med 3:1513-1524. doi:10.1371/journal.pmed.0030260

6. Stone AA, Shiffman S (1994) Ecological momentary assessment (EMA) in behavorial medicine. Ann Behav Med 16:199-202

7. Shiffman S, Stone AA, Hufford MR (2008) Ecological momentary assessment. Annu Rev Clin Psychol 4:1-32. doi:10. 1146/annurev.clinpsy.3.022806.091415

8. Kirchner TR, Shiffman S (2013) Ecological momentary assessment. In: MacKillop J, de Wit H (eds) The WileyBlackwell handbook of addiction psychopharmacology. WileyBlackwell, New York, pp 541-566

9. Bolger N, Davis A, Rafaeli E (2003) Diary methods: capturing life as it is lived. Annu Rev Psychol 54:579-616. doi:10.1146/ annurev.psych.54.101601.145030

10. Csikszentmihalyi M, Larson R (1987) Validity and reliability of the experience-sampling method. J Nerv Ment Dis 175:526-536. doi:10.1007/978-94-017-9088-8 
11. Csikszentmihalyi M, Larson R, Prescott S (1977) The ecology of adolescent activity and experience. J Youth Adolesc 6:281-294. doi:10.1007/BF02138940

12. Larson R, Csikszentmihalyi M, Freeman M (1984) Alcohol and marijuana use in adolescents' daily lives: a random sample of experiences. Int J Addict 19:367-381. doi:10.3109/ 10826088409057188

13. Matthews SA, Yang T-C (2013) Spatial polygamy and contextual exposures (SPACEs): promoting activity space approaches in research on place and health. Am Behav Sci 57:1057-1081. doi: $10.1177 / 0002764213487345$

14. Perchoux C, Chaix B, Cummins S, Kestens Y (2013) Conceptualization and measurement of environmental exposure in epidemiology: accounting for activity space related to daily mobility. Heal Place 21:86-93. doi:10.1016/j.healthplace.2013. 01.005

15. Lenntorp B (1977) Paths in space-time environments: a timegeographic study of movement possibilities of individuals. Environ Plan A 9:961-972

16. Saarloos D, Kim JE, Timmermans H (2009) The built environment and health: introducing individual space-time behavior. Int J Environ Res Public Health 6:1724-1743. doi:10.3390/ ijerph6061724

17. Epstein DH, Tyburski M, Craig IM et al (2014) Real-time tracking of neighborhood surroundings and mood in urban drug misusers: application of a new method to study behavior in its geographical context. Drug Alcohol Depend. doi:10.1016/j.dru galcdep.2013.09.007

18. Bronfenbrenner U (1979) The ecology of human development. Harvard University Press, Cambridge

19. Glass TA, McAtee MJ (2006) Behavioral science at the crossroads in public health: extending horizons, envisioning the future. Soc Sci Med 62:1650-1671. doi:10.1016/j.socscimed. 2005.08.044

20. Bandura A (2001) Social cognitive theory: an agentic perspective. Annu Rev Psychol. doi:10.1146/annurev.psych.52.1.1

21. Tooby J, Cosmides L (1992) The psychological foundations of culture. Adapt Mind Evol Psychol Gener Cult

22. Abramson DM, Stehling-Ariza T, Park YS et al (2010) Measuring individual disaster recovery: a socioecological framework. Disaster Med Public Health Prep 4:S46-S54. doi:10.1001/ dmp. 2010.14

23. Patrick K, Intille SS, Zabinski MF (2005) An ecological framework for cancer communication: implications for research. J Med Internet Res. doi:10.2196/jmir.7.3.e23

24. Cummins S, Curtis S, Diez-Roux AV, Macintyre S (2007) Understanding and representing "place" in health research: a relational approach. Soc Sci Med 65:1825-1838

25. Pezawas L, Meyer-Lindenberg A, Drabant EM et al (2005) 5-HTTLPR polymorphism impacts human cingulate-amygdala interactions: a genetic susceptibility mechanism for depression. Nat Neurosci 8:828-834. doi:10.1038/nn1463

26. Hariri AR, Mattay VS, Tessitore A et al (2002) Serotonin transporter genetic variation and the response of the human amygdala. Science 297:400-403. doi:10.1126/science.1071829

27. Twigger-Ross CL, Uzzell DL (1996) Place and identity processes. J Environ Psychol 16:205-220. doi:10.1006/jevp.1996. 0017

28. Proshansky HM, Fabian AK, Kaminoff R (1983) Place-identity: physical world socialization of the self. J Environ Psychol 3:57-83. doi:10.1016/S0272-4944(83)80021-8

29. de Vries MW (1992) The experience of psychopathology: investigating mental disorders in their natural settings. Cambridge University Press, Cambridge

30. Tooby J, Cosmides L (1990) The past explains the present. Emotional adaptations and the structure of ancestral environments. Ethol Sociobiol 11:375-424. doi:10.1016/01623095(90)90017-Z

31. Lende DH, Smith EO (2002) Evolution meets biopsychosociality: an analysis of addictive behavior. Addiction 97:447-458. doi:10.1046/j.1360-0443.2002.00022.x

32. Pollan M (2002) The botany of desire. Random House, New York

33. Richmond SJ, Keding A, Hover M et al (2015) Feasibility, acceptability and validity of SMS text messaging for measuring change in depression during a randomised controlled trial. BMC Psychiatr. doi:10.1186/s12888-015-0456-3

34. Aguilera A, Schueller SM, Leykin Y (2015) Daily mood ratings via text message as a proxy for clinic based depression assessment. J Affect Disord. doi:10.1016/j.jad.2015.01.033

35. Depp CA, Mausbach B, Granholm E et al (2010) Mobile interventions for severe mental illness: design and preliminary data from three approaches. J Nerv Ment Dis 198:715-721. doi:10.1097/NMD.0b013e3181f49ea3

36. Heron KE, Smyth JM (2010) Ecological momentary interventions: incorporating mobile technology into psychosocial and health behaviour treatments. Br $\mathrm{J}$ Health Psychol 15:1-39. doi:10.1348/135910709X466063

37. Matthews M, Voida S, Abdullah S et al (2015) In situ design for mental illness: considering the pathology of bipolar disorder in mHealth design. In: Proceedings of the 17th international conference human-computer interaction with mobile device service. ACM, New York, pp 86-97

38. Luxton DD, McCann RA, Bush NE et al (2011) mHealth for mental health: integrating smartphone technology in behavioral healthcare. Prof Psychol Res Pract 42:505-512. doi:10.1037/ a0024485

39. Peeters F, Nicholson NA, Berkhof J (2003) Cortisol responses to daily events in major depressive disorder. Psychosom Med. doi:10.1097/01.PSY.0000088594.17747.2E

40. Wenze SJ, Miller IW (2010) Use of ecological momentary assessment in mood disorders research. Clin Psychol Rev 30:794-804. doi:10.1016/j.cpr.2010.06.007

41. Axelson DA, Bertocci MA, Lewin DS et al (2003) Measuring mood and complex behavior in natural environments: use of ecological momentary assessment in pediatric affective disorders. J Child Adolesc Psychopharmacol 13:253-266. doi:10. 1089/104454603322572589

42. Myin-Germeys J, van Schwartz JE, van O Myin-Germeys I, Os J et al (2001) Emotional reactivity to daily life stress in psychosis. Arch Gen Psychiatry. doi:10.1001/archpsyc.58.12.1137

43. Hillbrand M, Waite BM, Miller DS et al (2000) Serum cholesterol concentrations and mood states in violent psychiatric patients: an experience sampling study. J Behav Med. doi:10. 1023/A:1005551418922

44. Delespaul P, deVries M, van Os J (2002) Determinants of occurrence and recovery from hallucinations in daily life. Soc Psychiatry Psychiatr Epidemiol. doi:10.1007/s001270200000

45. D'Antono B, Ditto B, Rios N, Moskowitz DS (1999) Risk for hypertension and diminished pain sensitivity in women: autonomic and daily correlates. Int J Psychophysiol 31:175-187. doi:10.1016/S0167-8760(98)00057-9

46. Whalen CK, Jamner LD, Henker B et al (2002) The ADHD spectrum and everyday life: experience sampling of adolescent moods, activities, smoking, and drinking. Child Dev 73:209-227. doi:10.1111/1467-8624.00401

47. Smyth J, Wonderlich S, Crosby R et al (2001) The use of ecological momentary assessment approaches in eating disorder research. Int J Eat Disord 30:83-95. doi:10.1002/eat.1057

48. Stein KF (1996) Affect instability in adults with a borderline personality disorder. Arch Psychiatr Nurs 10(32):40. doi:10. 1016/S0883-9417(96)80084-7 
49. Nisbett RE, Wilson TD (1977) Telling more than we can know: verbal reports on mental processes. Psychol Rev 84:231-259. doi:10.1037/0033-295X.84.3.231

50. Zajonc RB (1980) Feeling and thinking: preferences need no inferences. Am Psychol 35:151-175. doi:10.1037/0003-066X. 35.2 .151

51. Marteau TM, Hollands GJ, Fletcher PC (2012) Changing human behavior to prevent disease: the importance of targeting automatic processes. Science 337:1492-1495. doi:10.1126/science. 1226918

52. Panksepp J (2010) Affective neuroscience of the emotional BrainMind: evolutionary perspectives and implications for understanding depression. Dialog Clin Neurosci 12:533-545. doi:10.1016/S0140-6736(10)62052-1

53. Bargh JA, Ferguson MJ (2000) Beyond behaviorism: on the automaticity of higher mental processes. Psychol Bull 126:925

54. Wilson A (1970) Entropy in urban and regional modeling. Pion, London

55. Batty M (1976) Urban modelling: algorithms, calibrations, predictions. Cambridge University Press, Cambridge

56. Eagle N, Pentland AS, Lazer D (2009) Inferring friendship network structure by using mobile phone data. Proc Natl Acad Sci USA 106:15274-15278. doi:10.1073/pnas.0900282106

57. González MC, Hidalgo CA, Barabási A-L (2008) Understanding individual human mobility patterns. Nature 453:779-782. doi:10.1038/nature 07850

58. Simini F, Gonzalez MC, Maritan A, Barabasi A-L (2012) A universal model for mobility and migration patterns. Nature 484:96-100

59. Deville P, Linard C, Martin S et al (2014) Dynamic population mapping using mobile phone data. Proc Natl Acad Sci 111:15888-15893. doi:10.1073/pnas.1408439111

60. Editorial N (2008) A flood of hard data. Nature 435:698. doi:10. $1038 / 453698 \mathrm{a}$

61. Lazer D, Kennedy R, King G, Vespignani A (2014) The parable of Google flu: traps in big data analysis. Science 343:12031205. doi:10.1126/science. 1248506

62. Jensen SS (1998) Mapping human exposure to traffic air pollution using GIS. J Hazard Mater 385-392: doi:10.1016/S03043894(98)00139-3

63. Hertel O, Jensen SS, Andersen HV et al (2001) Human exposure to traffic pollution. Experience from Danish studies. Pure Appl Chem 73:137-145. doi:10.1351/pac200173010137

64. Phillips ML, Hall TA, Esmen NA et al (2001) Use of global positioning system technology to track subject's location during environmental exposure sampling. J Expo Anal Environ Epidemiol 11:207-215. doi:10.1038/sj.jea.7500161

65. Elgethun K, Fenske RA, Yost MG, Palcisko GJ (2003) Timelocation analysis for exposure assessment studies of children using a novel global positioning system instrument. Environ Health Perspect 111:115-122. doi:10.1289/ehp.5350

66. Gulliver J, Briggs DJ (2005) Time-space modeling of journeytime exposure to traffic-related air pollution using GIS. Environ Res 97:10-25. doi:10.1016/j.envres.2004.05.002

67. Seto EYW, Knapp F, Zhong B, Yang C (2007) The use of a vest equipped with a global positioning system to assess water-contact patterns associated with schistosomiasis. Geospat Health 1:233-241. doi:10.4081/gh.2007.271

68. Gerharz LE, Krüger A, Klemm O (2009) Applying indoor and outdoor modeling techniques to estimate individual exposure to PM2.5 from personal GPS profiles and diaries: a pilot study. Sci Total Environ 407:5184-5193. doi:10.1016/j.scitotenv.2009.06. 006

69. Setton E, Marshall JD, Brauer M et al (2011) The impact of daily mobility on exposure to traffic-related air pollution and health effect estimates. J Expo Sci Environ Epidemiol 21:42-48. doi:10.1038/jes.2010.14

70. Lioy PJ, Smith KR (2013) A discussion of exposure science in the 21st century: a vision and a strategy. Environ Health Perspect 121:405-409. doi:10.1289/ehp.1206170

71. Chokshi DA, Farley TA (2014) Changing behaviors to prevent noncommunicable diseases. Science 345:1243-1244. doi:10. 1126/science. 1259809

72. Juarez PD, Matthews-Juarez P, Hood DB et al (2014) The public health exposome: a population-based, exposure science approach to health disparities research. Int J Environ Res Public Health 11:12866-12895. doi:10.3390/ijerph111212866

73. Rainham DG, Bates CJ, Blanchard CM et al (2012) Spatial classification of youth physical activity patterns. Am J Prev Med. doi:10.1016/j.amepre.2012.02.011

74. Krenn PJ, Titze S, Oja P et al (2011) Use of global positioning systems to study physical activity and the environment a systematic review. Am J Prev Med 41:508-515. doi:10.1016/j. amepre.2011.06.046

75. Mccrorie PR, Fenton C, Ellaway A (2014) Combining GPS, GIS, and accelerometry to explore the physical activity and environment relationship in children and young people-a review. Int J Behav Nutr Phys Act 11:93. doi:10.1186/s12966014-0093-0

76. Almanza E, Jerrett M, Dunton G et al (2012) A study of community design, greenness, and physical activity in children using satellite, GPS and accelerometer data. Health Place 18:46-54. doi:10.1016/j.healthplace.2011.09.003

77. Rodríguez DA, Cho G-H, Evenson KR et al (2012) Out and about: association of the built environment with physical activity behaviors of adolescent females. Health Place 18:55-62. doi:10.1016/j.healthplace.2011.08.020

78. Troped PJ, Wilson JS, Matthews CE et al (2010) The built environment and location-based physical activity. Am J Prev Med 38:429-438. doi:10.1016/j.amepre.2009.12.032

79. Wiehe SE, Carroll AE, Liu GC et al (2008) Using GPS-enabled cell phones to track the travel patterns of adolescents. Int $\mathrm{J}$ Health Geogr 7:22. doi:10.1186/1476-072X-7-22

80. Zenk SN, Schulz AJ, Matthews SA et al (2011) Activity space environment and dietary and physical activity behaviors: a pilot study. Heal Place 17:1150-1161. doi:10.1016/j.healthplace. 2011.05.001

81. Jankowska MM, Schipperijn J, Kerr J (2015) A framework for using GPS data in physical activity and sedentary behavior studies. Exerc Sport Sci Rev 43:48-56. doi:10.1249/JES. 0000000000000035

82. Preston KL, Vahabzadeh M, Schmittner J et al (2009) Cocaine craving and use during daily life. Psychopharmacology 207:291-301. doi:10.1007/s00213-009-1655-8

83. McClernon FJ, Choudhury RR (2013) I am your smartphone, and i know you are about to smoke: the application of mobile sensing and computing approaches to smoking research and treatment. Nicotine Tob Res 15:1651-1654. doi:10.1093/ntr/ntt054

84. Dunton GF, Intille SS, Wolch J, Pentz MA (2012) Children's perceptions of physical activity environments captured through ecological momentary assessment: a validation study. Prev Med (Baltim) 55:119-121. doi:10.1016/j.ypmed.2012.05.015

85. Fukuoka Y, Kamitani E, Dracup K, Jong SS (2011) New insights into compliance with a mobile phone diary and pedometer use in sedentary women. J Phys Act Health 8:398-403. doi:10.1016/j.biotechadv.2011.08.021.Secreted

86. Spring B, Schneider K, McFadden HG et al (2012) Multiple behavior changes in diet and activity: a randomized controlled trial using mobile technology. Arch Intern Med 172:789-796. doi:10.1001/archinternmed.2012.1044 
87. Meliker JR, Sloan CD (2011) Spatio-temporal epidemiology: principles and opportunities. Spat Spatiotemporal Epidemiol 2:1-9. doi:10.1016/j.sste.2010.10.001

88. Nuckols JR, Ward MH, Jarup L (2004) Using geographic information systems for exposure assessment in environmental epidemiology studies. Environ Health Perspect 112:1007-1015. doi: $10.1289 /$ ehp. 6738

89. Whyte WH (1980) The social life of small urban spaces. Conservation Foundation, Washington, DC

90. Jacobs J (1961) The death and life of great American cities. Random House, New York, NY

91. Hirsch JA, Moore KA, Evenson KR et al (2013) Walk Score $(\mathrm{R})$ and Transit $\mathrm{Score}(\mathrm{R})$ and walking in the multi-ethnic study of atherosclerosis. Am J Prev Med 45:158-166. doi:10. 1016/j.amepre.2013.03.018

92. Leinberger CB, Lynch P (2014) Foot traffic ahead: ranking walkable urbanism in America's largest metros, Washington, DC

93. Noyes P, Pierre J, Lormel J et al (2014) Getting to school: a neighborhood report by the Harlem, Brooklyn and Bronx District Public Health Offices

94. Steinberg L, Cauffman E (1996) Maturity of judgment in adolescence: psychosocial factors in adolescent decision making. Law Hum Behav 20:249-272. doi:10.1007/BF01499023

95. Story M, Neumark-Sztainer D, French S (2002) Individual and environmental influences on adolescent eating behaviors. J Am Diet Assoc 102:S40-S51. doi:10.1016/S0002-8223(02)90421-9

96. Cairns G, Angus K, Hastings G, Caraher M (2013) Systematic reviews of the evidence on the nature, extent and effects of food marketing to children. A retrospective summary. Appetite 62:209-215. doi:10.1016/j.appet.2012.04.017

97. Morland K, Filomena S (2007) Disparities in the availability of fruits and vegetables between racially segregated urban neighbourhoods. Public Health Nutr 10:1481-1489. doi:10.1017/ S1368980007000079

98. Borradaile KE, Sherman S, Vander Veur SS et al (2009) Snacking in children: the role of urban corner stores. Pediatrics 124:1293-1298. doi:10.1542/peds.2009-0964

99. van der Horst K, Timperio A, Crawford D et al (2008) The school food environment. Associations with adolescent soft drink and snack consumption. Am J Prev Med 35:217-223. doi:10.1016/j.amepre.2008.05.022

100. Laska MN, Hearst MO, Forsyth A et al (2010) Neighbourhood food environments: are they associated with adolescent dietary intake, food purchases and weight status? Public Health Nutr 13:1757-1763. doi:10.1017/S1368980010001564

101. He M, Tucker P, Irwin JD et al (2012) Obesogenic neighbourhoods: the impact of neighbourhood restaurants and convenience stores on adolescents' food consumption behaviours. Public Health Nutr 15:1-9. doi:10.1017/S1368980012000584

102. Rossen LM, Curriero FC, Cooley-Strickland M, Pollack KM (2013) Food availability en route to school and anthropometric change in urban children. J Urban Heal 90:653-666. doi:10. 1007/s11524-012-9785-4

103. Timperio AF, Ball K, Roberts R et al (2009) Children's takeaway and fast-food intakes: associations with the neighbourhood food environment. Public Health Nutr 12:1960-1964. doi:10. 1017/S1368980009004959

104. Story M, Kaphingst KM, Robinson-O’ brien R, Glanz K (2008) Creating healthy food and eating environments: policy and environmental approaches. Annu Rev Public Health 29:253-272. doi:10.1146/annurev.publhealth.29.020907.090926

105. Rundle A, Neckerman KM, Freeman L et al (2009) Neighborhood food environment and walkability predict obesity in New York City. Environ Health Perspect 117:442-447. doi:10.1289/ ehp. 11590
106. Duncan DT, Sharifi M, Melly SJ et al (2014) Characteristics of walkable built environments and BMI $z$-scores in children: evidence from a large electronic health record database. Environ Health Perspect 122:1359-1365. doi:10.1289/ehp.1307704

107. Kestens Y, Lebel A, Chaix B et al (2012) Association between activity space exposure to food establishments and individual risk of overweight. PLoS One 7:e41418. doi:10.1371/journal. pone.0041418

108. Williams J, Scarborough P, Matthews A et al (2014) A systematic review of the influence of the retail food environment around schools on obesity-related outcomes. Obes Rev 15:359-374. doi:10.1111/obr.12142

109. Davis B, Carpenter C (2009) Proximity of fast-food restaurants to schools and adolescent obesity. Am J Public Health 99:505-510. doi:10.2105/AJPH.2008.137638

110. Curriero FC, James NT, Shields TM et al (2013) Exploring walking path quality as a factor for urban elementary school children's active transport to school. J Phys Act Health $10: 323-334$

111. Harrison F, Jones AP, van Sluijs EMF et al (2011) Environmental correlates of adiposity in 9-10 year old children: considering home and school neighbourhoods and routes to school. Soc Sci Med 72:1411-1419. doi:10.1016/j.socscimed.2011.02. 023

112. Kirchner TR, Anesetti-Rothermel A, Bennett M et al (2016) Tobacco outlet density and converted versus native non-daily cigarette use in a national US sample. Tob Control. doi:10.1136/ tobaccocontrol-2015-052487

113. Ogneva-Himmelberger Y, Ross L, Burdick W, Simpson S-A (2010) Using geographic information systems to compare the density of stores selling tobacco and alcohol: youth making an argument for increased regulation of the tobacco permitting process in Worcester, Massachusetts, USA. Tob Control 19:475-480

114. Peterson NA, Lowe JB, Reid RJ (2005) Tobacco outlet density, cigarette smoking prevalence, and demographics at the county level of analysis. Subst Use Misuse 40:1627-1635. doi:10.1080/ 10826080500222685

115. Peterson NA, Yu D, Morton CM et al (2011) Tobacco outlet density and demographics at the tract level of analysis in New Jersey: a statewide analysis. Drugs Educ Prev Policy 18:47-52

116. Reid RJ, Peterson NA, Lowe JB, Hughey J (2005) Tobacco outlet density and smoking prevalence: does racial concentration matter? Drugs Educ Prev Policy 12:233-238. doi:10.1080/ 09687630500035485

117. Reitzel LR, Cromley EK, Li Y et al (2011) The effect of tobacco outlet density and proximity on smoking cessation. Am J Public Health 101:315-320. doi:10.2105/AJPH.2010.191676

118. Yu D, Peterson NA, Sheffer MA et al (2010) Tobacco outlet density and demographics: analysing the relationships with a spatial regression approach. Public Health 124:412-416. doi:10. 1016/j.puhe.2010.03.024

119. Paul CL, Mee KJ, Judd TM et al (2010) Anywhere, anytime: retail access to tobacco in New South Wales and its potential impact on consumption and quitting. Soc Sci Med 71:799-806. doi:10.1016/j.socscimed.2010.05.011

120. Cantrell J, Pearson JL, Anesetti-Rothermel A et al (2016) Tobacco retail outlet density and young adult tobacco initiation. Nicotine Tob Res 18:130-137. doi:10.1093/ntr/ntv036

121. Chaiton M, Mecredy G, Rehm J, Samokhvalov AV (2014) Tobacco retail availability and smoking behaviours among patients seeking treatment at a nicotine dependence treatment clinic. Tob Induc Dis 12:19. doi:10.1186/1617-9625-12-19

122. Berke EM, Tanski SE, Demidenko E et al (2010) Alcohol retail density and demographic predictors of health disparities: a 
geographic analysis. Am J Public Health 100:1967-1971. doi:10.2105/AJPH.2009.170464

123. Kavanagh AM, Kelly MT, Krnjacki L et al (2011) Access to alcohol outlets and harmful alcohol consumption: a multi-level study in Melbourne, Australia. Addiction 106:1772-1779. doi:10.1111/j.1360-0443.2011.03510.x

124. Matthews SA, McCarthy JD, Rafail PS (2011) Using ZIP code business patterns data to measure alcohol outlet density. Addict Behav 36:777-780. doi:10.1016/j.addbeh.2011.02.009

125. Chaix B, Méline J, Duncan S et al (2013) GPS tracking in neighborhood and health studies: a step forward for environmental exposure assessment, a step backward for causal inference? Heal Place 21:46-51. doi:10.1016/j.healthplace.2013.01.003

126. Duncan MJ, Mummery WK (2007) GIS or GPS? A comparison of two methods for assessing route taken during active transport. Am J Prev Med 33:51-53. doi:10.1016/j.amepre.2007.02.042

127. Hurvitz PM, Moudon AV (2012) Home versus nonhome neighborhood: quantifying differences in exposure to the built environment. Am J Prev Med 42:411-417. doi:10.1016/j. amepre.2011.11.015

128. Harrison F, Burgoine T, Corder K et al (2014) How well do modelled routes to school record the environments children are exposed to?: a cross-sectional comparison of GIS-modelled and GPS-measured routes to school. Int J Health Geogr 13:5. doi:10. 1186/1476-072X-13-5

129. Kwan M-P, Peterson RD, Browning CR et al (2008) Reconceptualizing sociogeographic context for the study of drug use, abuse and addiction. In: Thomas YF, Richardson D, Cheung I (eds) Geography and Drug Addiction, Springer, Netherlands, pp 437-446

130. Kirchner TR, Cantrell J, Anesetti-Rothermel A et al (2012) Individual mobility patterns and real-time geo-spatial exposure to point-of-sale tobacco marketing. In: Proceedings of the conference on wireless health. ACM, pp 1-8. doi:10.1145/2448096.2448104

131. Carlos HA, Shi X, Sargent J et al (2010) Density estimation and adaptive bandwidths: a primer for public health practitioners. Int J Health Geogr 9:39. doi:10.1186/1476-072X-9-39

132. Pearson JL, Smiley SL, Rubin LF et al (2016) The moment study: protocol for a mixed method observational cohort study of the alternative nicotine delivery systems (ANDS) initiation process among adult cigarette smokers. BMJ Open 6:e011717. doi:10.1136/bmjopen-2016-011717

133. Chaix B, Kestens Y, Perchoux C et al (2012) An interactive mapping tool to assess individual mobility patterns in neighborhood studies. Am J Prev Med 43:440-450

134. Christian WJ (2012) Using geospatial technologies to explore activity-based retail food environments. Spat Spatiotemporal Epidemiol 3:287-295. doi:10.1016/j.sste.2012.09.001

135. Kirchner TR, Cantrell J, Anesetti-Rothermel A et al (2013) Geospatial exposure to point-of-sale tobacco: real-time craving and smoking-cessation outcomes. Am J Prev Med 45:379-385. doi:10.1016/j.amepre.2013.05.016

136. Watkins KL, Regan SD, Nguyen N et al (2014) Advancing cessation research by integrating EMA and geospatial methodologies: associations between tobacco retail outlets and realtime smoking urges during a quit attempt. Nicotine Tob Res 16:S93-S101. doi:10.1093/ntr/ntt135

137. Epstein DH, Willner-Reid J, Vahabzadeh M et al (2009) Realtime electronic diary reports of cue exposure and mood in the hours before cocaine and heroin craving and use. Arch Gen Psychiatry 66:88-94. doi:10.1001/archgenpsychiatry.2008.509

138. Epstein DH, Marrone GF, Heishman SJ et al (2010) Tobacco, cocaine, and heroin: craving and use during daily life. Addict Behav 35:318-324. doi:10.1016/j.addbeh.2009.11.003

139. Berkman ET, Dickenson J, Falk EB, Lieberman MD (2011) Using SMS text messaging to assess moderators of smoking reduction: validating a new tool for ecological measurement of health behaviors. Health Psychol 30:186-194. doi:10.1037/ a0022201

140. Delfino RJ, Jamner LD, Whalen CK (2001) Temporal analysis of the relationship of smoking behavior and urges to mood states in men versus women. Nicotine Tob Res 3:235-248. doi:10. 1080/14622200110050466

141. Wileyto EP, Patterson F, Niaura R et al (2005) Recurrent event analysis of lapse and recovery in a smoking cessation clinical trial using bupropion. Nicotine Tob Res 7:257-268. doi:10. 1080/14622200500055673

142. Kennedy AP, Epstein DH, Jobes ML et al (2015) Continuous inthe-field measurement of heart rate: correlates of drug use, craving, stress, and mood in polydrug users. Drug Alcohol Depend 151:159-166. doi:10.1016/j.drugalcdep.2015.03.024

143. Beckham JC, Wiley MT, Miller SC et al (2008) Ad lib smoking in post-traumatic stress disorder: an electronic diary study. Nicotine Tob Res 10:1149-1157. doi:10.1080/ 14622200802123302

144. Armeli S, Dehart T, Tennen H et al (2007) Daily interpersonal stress and the stressor-vulnerability model of alcohol use. J Soc Clin Psychol 26:896-921. doi:10.1521/jscp.2007.26.8.896

145. Hull JG, Slone LB (2004) Self-regulatory failure and alcohol use. In: Baumeister RF, Vohs KD (eds) Handbook of self-regulation: research, theory, and applications. Guilford Press, New York, pp 466-491

146. Sayette MA, Creswell KG (2010) Self-regulatory failure and addiction. In: Baumeister RF, Vohs KD (eds) Handbook of selfregulation: research, theory, and applications, 3rd edn. Guilford Press, New York, pp 571-590

147. Mason MJ, Korpela K (2009) Activity spaces and urban adolescent substance use and emotional health. J Adolesc. doi:10. 1016/j.adolescence.2008.08.004

148. Burns MN, Begale M, Duffecy J et al (2011) Harnessing context sensing to develop a mobile intervention for depression. J Med Internet Res. doi:10.2196/jmir.1838

149. Bogomolov A, Lepri B, Ferron M, et al (2014) Daily stress recognition from mobile phone data, weather conditions and individual traits. In: Proceedings of the ACM international conference on multimedia, MM'14, pp 477-486. doi:10.1145/ 2647868.2654933

150. Madan A, Cebrian M, Lazer D, Pentland A (2010) Social sensing for epidimiological behavior change. In: UbiComp 10, Proceedings of the 12th ACM international conference on ubiquitous computing, pp 291-300

151. Canzian L, Musolesi M (2015) Trajectories of depression: unobtrusive monitoring of depressive states by means of smartphone mobility traces analysis. In: Proceedings of the 2015 ACM international joint conference on pervasive ubiquitous computing, pp 1293-1304. doi:10.1145/2750858.2805845

152. Saeb S, Zhang M, Karr CJ et al (2015) Mobile phone sensor correlates of depressive symptom severity in daily-life behavior: an exploratory study. J Med Internet Res 17:e175. doi:10.2196/ jmir.4273

153. Clougherty JE, Levy JI, Kubzansky LD et al (2007) Synergistic effects of traffic-related air pollution and exposure to violence on urban asthma etiology. Environ Health Perspect 115:1140-1146. doi:10.1289/ehp.9863

154. McEwen BS, Stellar E (1993) Stress and the individual: mechanisms leading to disease. Arch Int Med 153:2093-2101

155. Hu Z, Liebens J, Rao KR (2008) Linking stroke mortality with air pollution, income, and greenness in northwest Florida: an ecological geographical study. Int J Health Geogr 7:20. doi:10. 1186/1476-072X-7-20

156. Szyszkowicz M (2007) Air pollution and emergency department visits for depression in Edmonton, Canada. Int J Occup Med Environ Health 20:241-245. doi:10.2478/v10001-007-0024-2 
157. Lim Y-H, Kim H, Kim JH et al (2012) Air pollution and symptoms of depression in elderly adults. Environ Health Perspect 120:1023-1028. doi:10.1289/ehp.1104100

158. Bullinger M (1989) Psychological effects of air pollution on healthy residents - a time-series approach. J Environ Psychol 9:103-118. doi:10.1016/S0272-4944(89)80002-7

159. Abramson DM, Van Alst D, Merdjanoff A et al (2015) The hurricane sandy person report: disaster exposure, health impacts, economic burden, and social well-Being. Sandy Child and Family Health Study, Briefing Report 2015_2

160. David P, Buckworth J, Pennell ML et al (2012) A walking intervention for postmenopausal women using mobile phones and interactive voice response. J Telemed Telecare 18:20-25. doi:10.1258/jtt.2011.110311

161. Dunton GF, Liao Y, Intille SS et al (2011) Investigating children's physical activity and sedentary behavior using ecological momentary assessment with mobile phones. Obesity (Silver Spring) 19:1205-1212. doi:10.1038/oby.2010.302

162. Sternfeld B, Jiang SF, Picchi T et al (2012) Evaluation of a cell phone-based physical activity diary. Med Sci Sports Exerc 44:487-495. doi:10.1249/MSS.0b013e3182325f45

163. Liao $Y$, Intille $S$, Wolch $J$ et al (2014) Understanding the physical and social contexts of children's nonschool sedentary behavior: an ecological momentary assessment study. J Phys Act Health 11:588-595. doi:10.1123/jpah.2011-0363

164. Block ML, Wu X, Pei Z et al (2004) Nanometer size diesel exhaust particles are selectively toxic to dopaminergic neurons: the role of microglia, phagocytosis, and NADPH oxidase. FASEB J 18:1618-1620. doi:10.1096/fj.04-1945fje

165. Glenister D (1996) Exercise and mental health: a review. J R Soc Promot Health 116:7-13. doi:10.1177/146642409611600102

166. Craft LL, Landers DM (1998) The effect of exercise on clinical depression and depression resulting from mental illness: a metaanalysis. J Sport Exerc Psychol 20:339-357. doi:10.1097/ 00005768-199805001-00666

167. Lawlor DA, Hopker SW (2001) The effectiveness of exercise as an intervention in the management of depression: systematic review and meta-regression analysis of randomised controlled trials. BMJ 322:763-767. doi:10.1136/bmj.322.7289.763

168. Ohta M, Mizoue T, Mishima N, Ikeda M (2007) Effect of the physical activities in leisure time and commuting to work on mental health. J Occup Health 49:46-52. doi:10.1539/joh.49.46

169. Bursik RJ (1988) Social disorganization and theories of crime and delinquency: problems and prospects. Criminology (Beverly Hills) 26:519-552. doi:10.1111/j.1745-9125.1988.tb00854.x

170. Shaw CR, McKay HD (1942) Juvenile delinquency and urban areas. University of Chicago Press, Chicago

171. Galea S, Ahern J, Tracy M et al (2008) Longitudinal determinants of posttraumatic stress in a population-based cohort study. Epidemiology 19:47-54. doi:10.1097/EDE.0b013e31815c1dbf

172. Goldmann E, Aiello A, Uddin M et al (2011) Pervasive exposure to violence and posttraumatic stress disorder in a predominantly African American Urban Community: the Detroit neighborhood health study. J Trauma Stress 24:747-751. doi:10.1002/jts. 20705

173. Furr-Holden CDM, Smart MJ, Pokorni JL et al (2008) The NIfETy method for environmental assessment of neighborhoodlevel indicators of violence, alcohol, and other drug exposure. Prev Sci 9:245-255. doi:10.1007/s11121-008-0107-8

174. Boardman Jason D, Finch BK, Ellison CG et al (2001) Neighborhood disadvantage, stress, and drug use among adults. J Health Soc Behav 42:151-165. doi:10.2307/3090175

175. Nandi A, Galea S, Ahern J et al (2006) What explains the association between neighborhood-level income inequality and the risk of fatal overdose in New York City? Soc Sci Med 63:662-674. doi:10.1016/j.socscimed.2006.02.001
176. Wills TA, Sandy JM, Yaeger AM et al (2001) Coping dimensions, life stress, and adolescent substance use: a latent growth analysis. J Abnorm Psychol 110:309-323. doi:10.1037//002I843X.110.2.309

177. Davis JR, Tunks E (1991) Environments and addiction: a proposed taxonomy. Int J Addict 25:805-826

178. Dishion TJ, Connell A (2006) Adolescents' resilience as a selfregulatory process. Ann N Y Acad Sci 1094:125-138. doi:10. 1196/annals.1376.012

179. Fitzpatrick K, LaGory M (2004) Unhealthy places: the ecology of risk in the urban landscape. Taylor \& Francis, London

180. Tolan PH, Gorman-Smith D, Henry D et al (2002) The relation of patterns of coping of inner-city youth to psychopathology symptoms. J Res Adolesc 12:423-449

181. Korpela KM, Kyttä M, Hartig T (2002) Restorative experience, self-regulation and children's place preferences. J Environ Psychol 22:387-398. doi:10.1006/jevp.2002.0277

182. Low SM, Altman I (1992) Place attachment: a conceptual inquiry. Place Attach 1-12

183. Latkin CA, Curry AD (2003) Stressful neighborhoods and depression: a prospective study of the impact of neighborhood disorder. J Health Soc Behav 44:34-44

184. Airey L (2003) "Nae as nice a scheme as it used to be": lay accounts of neighbourhood incivilities and well-being. Heal Place. doi:10.1016/S1353-8292(03)00013-3

185. Popay J, Thomas C, Williams G et al (2003) A proper place to live: health inequalities, agency and the normative dimensions of space. Soc Sci Med. doi:10.1016/S0277-9536(02)00299-X

186. Goldmann E, Galea S (2014) Mental health consequences of disasters. Annu Rev Public Health 35:169-183. doi:10.1146/ annurev-publhealth-032013-182435

187. Abramson DM, Park YS, Stehling-Ariza T, Redlener I (2010) Children as bellwethers of recovery: dysfunctional systems and the effects of parents, households, and neighborhoods on serious emotional disturbance in children after Hurricane Katrina. Disaster Med Public Health Prep 4:S17-S27

188. Abramson, DM, Redlener IE, Stehling-Ariza T et al (2010) Impact on children and families of the deepwater horizon oil spill: preliminary findings of the coastal population impact study, Columbia University Academic Commons. http://hdl. handle.net/10022/AC:P:9416

189. Abramson DM, Grattan LM, Mayer B et al (2015) The resilience activation framework: a conceptual model of how access to social resources promotes adaptation and rapid recovery in postdisaster settings. J Behav Health Serv Res 42:42-57

190. Sherrieb K, Norris FH, Galea S (2010) Measuring capacities for community resilience. Soc Indic Res 99:227-247. doi:10.1007/ s11205-010-9576-9

191. Cutter SL, Boruff BJ, Shirley WL (2003) Social vulnerability to environmental hazards. Soc Sci Q 84:242-261. doi:10.1111/ 1540-6237.8402002

192. National Institutes of Health (2014) Computing challenges in future mobile health (mHealth) systems and applications-vision paper. https://sites.google.com/site/mhealthworkshop2014/vision-paper

193. Griffith DA, Jones KG (1980) Explorations into the relationship between spatial structure and spatial interaction. Environ Plan A 12:187-201

194. Waller LA, Gotway CA (2004) Applied spatial statistics for public health data. Wiley, Hoboken

195. Paty JA, Kassel JD, Shiffman S (1992) Assessing stimulus control of smoking: the importance of base rates. In: DeVries M (ed) The Experience of Psychopathology. Cambridge University Press, Cambridge, UK, pp 347-352

196. Carter BL, Lam CY, Robinson JD et al (2008) Real-time craving and mood assessments before and after smoking. Nicotine Tob Res 10:1165-1169. doi:10.1080/14622200802163084 
197. Shiffman S, Paty JA, Gwaltney CJ, Dang Q (2004) Immediate antecedents of cigarette smoking: an analysis of unrestricted smoking patterns. J Abnorm Psychol 113:166-171. doi:10.1037/ 0021-843X.113.1.166

198. Mun M, Reddy S, Shilton K, Yau N (2009) PEIR, the personal environmental impact report, as a platform for participatory sensing systems research. MobiSys. doi:10.1145/1555816. 1555823

199. Shilton K (2009) Four billion little brothers?: privacy, mobile phones, and ubiquitous data collection. Commun ACM 7:40-47. doi: $10.1145 / 1592761.1592778$

200. Shilton K, Sayles S (2016) "We aren't all going to be on the same page about ethics": ethical practices and challenges in research on digital and social media. In: 2016 49th Hawaii international conference system science. IEEE, New York, pp 1909-1918

201. Lane J, Stodden V, Bender S, Nissenbaum H (2014) Privacy, big data, and the public good: frameworks for engagement. Cambridge University Press, Cambridge

202. House B (2013) Openpaths: empowering personal geographic data. In: Proceedings of the ISEA, Sydney, Australia. https://ses. library.usyd.edu.au//bitstream/2123/9719/1/openpathsempowering. pdf

203. Helliwell JF, Layard R, Sachs J (2015) World happiness report 2015. Sustainable Development Solutions Network, New York

204. Gallup, Healthways. Gallup-Healthways Well-Being Index: methodology report for indexes. http://www.well-beingindex. com/. Accesssed June 2016

205. Gallup Healthways Well-Being Index (2015) State Well-Being Rankings Analysis. http://info.healthways.com/hubfs/Well-Being_
Index/2015_Data/Gallup-Healthways_State_of_American_WellBeing_2015_State_Rankings.pdf. Accesssed June 2016

206. Golder SA, Macy MW (2011) Diurnal and seasonal mood vary with work, sleep, and daylength across diverse cultures. Science (80) 333:1878-1881. doi:10.1126/science.1202775

207. Mislove A, Lehmann S, Ahn Y-Y, et al (2010) U.S. mood throughout the day inferred from Twitter. http://www.ccs.neu. edu/home/amislove/twittermood/

208. Mitchell L, Frank MR, Harris KD et al (2013) The geography of happiness: connecting Twitter sentiment and expression, demographics, and objective characteristics of place. PLoS One. doi:10.1371/journal.pone.0064417

209. Ilakkuvan V, Tacelosky M, Ivey KC et al (2014) Cameras for public health surveillance: a methods protocol for crowdsourced annotation of point-of-sale photographs. J Med Internet Res 16:1-10. doi:10.2196/resprot.3277

210. Abdullah S, Murnane EL, Costa JMR, Choudhury T (2015) Collective smile: measuring societal happiness from geolocated images. In: Proceedings of the 18th ACM conference on computer supported cooperative work and social computing, CSCW'15, pp 361-374

211. Cantrell J, Ganz O, Ilakkuvan V et al Implementation of a multimodal mobile system for point-of-sale surveillance: lessons learned from case studies in Washington, DC, and New York city. JMIR Public Heal Surveill 1:e20. doi:10.2196/publichealth. 4191

212. Diez Roux AV (2008) Next steps in understanding the multilevel determinants of health. J Epidemiol Community Health 62:957-959. doi:10.1136/jech.2007.064311 